\title{
DISEASE ACTIVITY IN PATIENTS WITH PSORIATIC ARTHRITIS: A MOLDAVIAN STUDY
}

\section{Tatiana ROTARU1 ${ }^{\bowtie}$, Maria GARABAJIU ${ }^{2}$, Lucia MAZUR-NICORICI ${ }^{3}$, Natalia LOGHIN-OPREA ${ }^{3}$, Victoria SADOVICI-BOBEICA ${ }^{3}$, Virginia SALARU ${ }^{2}$, Minodora MAZUR ${ }^{3}$}

${ }^{1}$ Institute of Cardiology, Chisinau, Republic of Moldova

2 Department of Family Medicine, "Nicolae Testemitanu" State University of Medicine and Pharmacy, Chisinau, Republic of Moldova

${ }^{3}$ Department of Internal Medicine, "Nicolae Testemitanu" State University of Medicine and Pharmacy, Chisinau, Republic of Moldova

Received 21 Jan 2021, Accepted 27 Febr 2021

https://doi.org/10.31688/ABMU.2021.56.1.04

\section{Abstract}

Introduction. Psoriatic arthritis (PsA) is an inflammatory joint disease associated in up to one-third of patients with psoriasis. Studies performed on PsA showed the high burden of the disease, but it still has not been totally quantified due to variable course of the disease. The applicability of the existing clinical tools in the disease activity appreciation still needs to be approved.

The objective of the study was the assessment of the disease activity level and the evaluation of reliability and applicability of disease activity measures in PsA.

Materials and methods. A descriptive study of 46 PsA patients was performed. The disease activity indices for PsA were evaluated and compared. The level of the disease activity according to each index was assessed and applicability of these indices was appreciated.

Results. The disease activity by Disease Activity Index for Psoriatic Arthritis (DAPSA) was appreciated as moderate in nearly half of the patients (47.8\%), and according to Bath Ankylosing Spondylitis Disease

\section{RÉSUMÉ}

Lactivité de la maladie chez les patients avec arthrite psoriasique : une étude Moldave

Introduction. Larthrite psoriasique (APs) est une maladie articulaire inflammatoire qui atteint un tiers des patients avec psoriasis cutané. Les études sur l'APs ont démontré que les patients supportent une charge importante, mais celle-ci n'a pas été totalement quantifiée en raison de l'évolution variable de la maladie. Toutefois, l'applicabilité des outils cliniques existants dans l'appréciation de l'activité de la maladie doit encore être étudiée.

L'objectif de l'étude a été d'évaluer le niveau d'activité de la maladie et d'apprécier la fiabilité et de l'applicabilité des mesures de l'activité de la maladie des patients avec APs.

Matériel et méthodes. Nous avons effectué une étude descriptive de 46 patients avec APs. Les indices d'activité de la maladie ont été évalués et comparés. L'activité de la maladie selon chaque indice a été évaluée et l'applicabilité de ces indices a été estimée. 
Activity Index (BASDAI) moderate disease activity was assessed in 56.5\% cases. Minimal disease activity was encountered in only $8.69 \%$ of patients. Psoriasis Area and Severity Index (PASI) was estimated as moderate (mean 20.21 points). The data analysis of clinical tools showed that the most affected were pain and general condition, objectified by Visual Analogue Scale (VAS) and Patient Global Assessment (PGA).

Conclusions. The DAPSA demonstrated the highest objectiveness and was best able to designate between different levels of disease activity. DAPSA together with Minimal Disease Activity index (MDA), were best related to patient's quality of life. Therefore, assessing the activity of the disease by MDA and DAPSA can be recommended for use in clinical practice.

Keywords: psoriatic arthritis, disease activity measure, quality of life.

\section{List of abbreviations:}

PsA - Psoriatic arthritis

DAPSA - Disease Activity Index for Psoriatic Arthritis

BASDAY - Bath Ankylosing Spondylitis Disease Activity Index

PASI - Psoriasis Area and Severity Index

VAS - Visual Analogue Scale

PGA - Patient Global Assessment

MDA - Minimal Disease Activity index

LDI - Leeds Dactylitis Instrument

MASES - Maastricht Ankylosing Spondylitis Enthesis

Score

MDGA - Medical Doctor Global Assessment

TJC - Tender Joint Count

SJC - Swollen Joint Count

HAQ - Health Assessment Questionnaire

ESR - Erythrocyte Sedimentation Rate

CRP - C-reactive Protein

HRQoL - Health Related Quality of Life

\section{INTRODUCTION}

Psoriatic arthritis (PsA) is an inflammatory joint disease associated with cutaneous disease, psoriasis, or found in patients with a family history of psoriasis. The frequency of PsA among patients with psoriasis varies from study to study, the fluctuation of the involvement may be significantly different and varies considerably (range 6\%-41\%) depending on definitions used (ex. classification criteria, diagnostic codes, rheumatologist diagnosis) ${ }^{1}$. While PsA is associated with psoriasis, clinical and observational studies suggest that the cumulative incidence of PsA is increasing over time in patients with psoriasis and reported $1.7 \%, 3.1 \%$, and $5.1 \%$, respectively at 5,10 , and 20 years after the diagnosis of psoriasis ${ }^{2}$.
Résultats. L'activité de la maladie par DAPSA a été appréciée comme modérée chez $47.8 \%$ des patients, selon BASDAI, l'activité modérée de la maladie a été établie dans $56.5 \%$ des cas. Lactivité minimale de la maladie n'a été rencontrée que chez $8.69 \%$ des patients. L'activité cutanée par PASI était modérée (moyenne de 20.21 points). L'analyse des données des outils cliniques a montré que les plus affectés étaient la douleur et l'état général, objectivés par l'échelle visuelle analogue et l'évaluation globale des patients.

Conclusions. Lactivité de la maladie appréciée par DAPSA a démontré une plus grande objectivité, et a prouvé sa supériorité de décision sur les différents niveaux d'activité de la maladie. Le DAPSA associé à l'indice d'activité minimale de la maladie (MDA) étaient mieux corrélés à la qualité de vie des patients. Par conséquence, l'évaluation de l'activité de la maladie à travers MDA et DAPSA peut être recommandée pour l'utilisation dans la pratique clinique.

Mots-clés: arthrite psoriasique, mesure de l'activité de la maladie, qualité de la vie.

PsA is a clinically heterogeneous disorder. In addition, the spectrum of the disease features can vary from mild to very severe, representing a challenge for the physician. It is well-known that patients can have any combination of the disease features: peripheral arthritis, enthesitis, dactylitis, spondylitis or sacroiliitis, as well as psoriatic nail disease. Peripheral arthritis is the most common disease manifestation. Another key disease manifestation is enthesitis, defined as inflammation at sites of tendon and ligament attachments. Enthesites may be asymptomatic or painful and can affect the patient's function and quality of life, being present in more than half of the patients ${ }^{3}$. Dactylitis, defined as inflammatory swelling of the entire digit, which can be present in either 
the feet or the hand, is a typical feature affecting up to $40 \%$ of PsA patients ${ }^{3}$. Axial arthritis is found in up to $40 \%$ of patients, however only around $2 \%$ have pure axial disease ${ }^{3}$. Nail lesions can be present in about $87 \%$ of these patients. Other manifestations, in common with other spondylarthrites such as uveitis, urethritis, inflammatory bowel disease, mucous membrane lesions and aortic root dilatation, are relatively uncommon ${ }^{3}$.

The outcomes in rheumatic diseases have improved significantly over the last decades, largely due to the designation of new therapies and their use in treat-to-target (T2T) strategies, although these recommendations are available in PsA. The main objective of T2T strategies is achieving remission or a low/ minimal disease activity. Due to the variety of the disease manifestations and the fact that most patients do not have symptoms in every area (included in pathological process), each of the systems implicated must be considered when formulating treatment targets. According to these strategies, the disease activity is measured at every stage of the disease, firstly at the onset, for immediate initiation of the specific treatment regimen.

The disease activity in arthritis is assessed using composite measures, in which multiple aspects of the disease are combined in a total score. For example, in rheumatoid arthritis guiding the treatment based on measuring the disease activity with the Disease Activity Score - 28 (DAS-28) has improved care and long-term outcomes. Although multiple disease activity measures are available and used in the research of PsA, no consensus has been reached on which tool should be used ${ }^{4,5}$. The assessment of the overall impact of the disease on individual patient's embracement of additional issues such as pain, loss of function and impairment of quality of life in addition to classical physician-assessed domains of the disease activity may be useful. The group for Research and Assessment of Psoriasis and Psoriatic Arthritis/Outcome Measure in Rheumatology (GRAPPA-OMERACT) has developed a core domain set for PsA, which spotlight the domains relevant to this pathology to define the concept. The circle on the inside of the core is recommended to be quantified in all clinical trials and includes musculoskeletal and skin disease activity, pain, patient and physician global assessment, physical function, fatigue and systemic inflammatory markers. As a more PsA-specific measure, the Disease Activity index for Psoriatic Arthritis (DAPSA) was developed using 66/68 instead of 28 joint count, rising the sensibility of this index. The DAPSA furnishes a continuous score of arthritis activity and provides a validated cut points for remission $(<4)$ and low disease activity $(<14)^{6}$. At the same time, recent research has concentrated on polyarticular patients, in whom the disease activity is proportional to joints counts but may be less illustrative in oligo-arthritis patients in whom despite the high impact of disease, the DAPSA high disease activity cut point is unlikely to ever be reached.

Axial disease in PsA is perhaps the least well-quantified feature of the disease. Significant issues are also being encountered with the outcome measures used in axial PsA. Thus, the Bath Ankylosing Spondylitis Disease Activity Index (BASDAI) has been used to measure disease activity in axial PsA and has been shown a good correlation with other disease activity indices. However, it is not able to provide a clear differentiation between axial and peripheral musculoskeletal disease activity with high scores in patients with active peripheral PsA only. Dactylitis, as a component part of the PsA picture, has its impact to the patient's general condition, by amplifying the disease activity. The only validated tool for assessing dactylitis is the Leeds Dactylitis Instrument (LDI), developed in response to the need for a clinical, objective tool. It measures the ratio of the circumference of the affected digit to the circumference of the digit on the contra-lateral hand or foot: a minimum difference of $10 \%$ is used to define a dactylitic digit. Enthesitis is a unique and important clinical feature of spondyloarthropathy. The Mander Enthesis Index (MEI), the Maastricht Ankylosing Spondylitis Enthesis Score (MASES), the SPondylArthritis Research Consortium of Canada (SPARCC) index, and the Major Enthesitis Index (MEI) were all developed and validated for patients with PsA. Despite on this, the Leeds Enthesitis Index (LEI), which was published in 2008 , is the only measure developed specifically for PsA?

The Psoriasis Area and Severity Index (PASI) was developed to provide a quantitative assessment of psoriasis lesion burden based on the BSA index involved in specific patient and degree of severity of erythema, induration, and scale, weighted by body part. PASI is the best-validated score for defining disease severity in psoriasis vulgaris. The primary endpoint in psoriasis trials and the key skin endpoint in PsA trials are PASI responses. Nail psoriasis is assessed using the nail psoriasis severity index (NAPSI) or modified NAPSI ${ }^{8}$.

Patient global assessment (PGA) of disease activity is important because it enhances the patient-physician interaction and highlights the global influences of PsA on the patient's well-being. The specific question for PGA was "In all the ways in which your psoriasis and arthritis, as a whole, affect you, how would you rate the way you felt over the past week?" Results showed that PGA with a single question addressing 
both joint and skin disease is a reliable and responsive measure in assessing patient in totality9.

The appreciation of the disease activity is the basis in the evaluation of the patient with PsA and is crucial in the election of the treatment strategy, continuous managing the response treatment with the goal of achieving remission or a low/minimal disease activity. This state of the disease signifies that its burden at that time is low and long-term worsening of functioning, quality of life and joint erosion are prevented, and subsequently the prognosis in these conditions is improved. However, for all the presence of the numerous disease activity evaluation tools, the burden of PsA is still high and the reliability of existent tools has to be justified.

The objective of THE STUDY was to assess the disease activity level and the evaluation of reliability and applicability of disease activity measures in PsA.

\section{Materials AND Methods}

A descriptive study was conducted between May 2019 and March 2020 in the Rheumatology Department of the Institute of Cardiology, Chisinau, Republic of Moldova. The patients of the study group were selected consecutively and formed a group of 46 subjects with the diagnosis of psoriatic arthritis. The study included patients aged over 18 years old, who signed an informed consent to participate in the study and with the pre-established diagnosis of psoriatic arthritis. The exclusion criteria included rheumatoid arthritis and arthritis of other etiology, as well as patient's refusal. The investigative results were accumulated according to our approved research questionnaire, which contains information on clinical and demographic data: sex, place of residence, marital status, age at onset and duration of disease, patient's profession and education, as well as characteristics of the disease evaluated by specific clinical tools.

According to the aim of the study, the level of the PsA disease activity was quantified by DAPSA, considered gold standard for this disease, and BASDAI which is largely used for reactive arthritis. Regarding to a specifically appreciation of a Minimal Disease Activity (MDA), we aimed to determine the rate of remissions and low disease activity in our patients. To calculate disease activity indices, there where appreciated the following components: a full traditional 66/68 evaluation of TJC/SJC, as well as joint pain appreciated by visual analogue scale (VAS), the global assessment of the patient's condition by estimating PGA (Patient Global Assessment) and MDGA (Medical Doctor Global Assessment), appreciated by
$100 \mathrm{~mm}$ scale. Simultaneously, to provide a quantitative assessment of psoriasis lesion burden based on the amount of BSA involved and degree of severity of erythema, induration, and scale, weighted by body part, PASI was evaluated. Furthermore, MASES, recommended by the Spondylarthritis International Society for use in randomized controlled trials of axial spondylitis and spondylarthritis, was used to assess enthesitis in our study patients. Physical function was reliably assessed in our patients by using Health Assessment Questionnaire (HAQ), which is a component of MDA index.

The study was conducted in accordance with the Helsinki Declaration on Human Rights, as well as the national law. The study design was approved by the Ethics Committee of the Institute of Cardiology, Chisinau (24 December 2012). Written informed consent was obtained from all participants, according to the Declaration of Helsinki.

The statistical processing of the research data was carried out with the help of Microsoft Excel and MedCalc v.1.2 programs. The mean values (M), the arithmetic mean $(t)$, and the validity of the differences $\mathrm{p}$ according to Student's t-distribution were evaluated and displayed in boxplot. The difference in indices was considered probable at $\mathrm{p}<0.05$ according to Student's t-test distribution. The degree of correlation was calculated by the Pearson test, where absolute value of $r$ and strength of $r$ was considered: $r<$ 0.3 none or very weak, $0.3<\mathrm{r}<0.5$ weak, $0.5<\mathrm{r}<0.7$ moderate and $r>0.7$ strong.

\section{Results}

In accordance with the established tasks, the study group included 46 patients with PsA who met the pre-established inclusion criteria. We analyzed the demographic parameters in the examined patients; the obtained results were shown in Table 1. The data reveal the predominance of men (54.35\%) in the study group, with a female to male ratio of 1.19: 1 . After the segregation of the subjects from the study group according to the place of residence, we highlighted their preponderance in the urban space. Next, we analyzed the marital status of patients and found that $80.43 \%$ of patients lived with families, being married, $8.04 \%$ were divorced and $4.35 \%$ single at the time of research. $6.52 \%$ of the subjects included in the study were widows(ers). We took into account the persons living with the study patients at the moment of the examination and found that $41.3 \%$ and $47.83 \%$ of patients lived with their spouse, partner or children, when every tenth person lived alone. Afterward, we were interested in assessing the disease risk factors, finding that $56.52 \%$ of cases did 
Table 1. Demographic data of patients in the study group

\begin{tabular}{ccc}
\hline Variable & Patients, No & (\%) \\
\hline Gender: & & \\
Women & 21 & 45.65 \\
Men & 25 & 54.35 \\
\hline Place of residence: & & \\
Rural & 22 & 47.83 \\
Urban & 24 & 52.17 \\
\hline Marital status: & & \\
Married & 37 & 80.43 \\
Divorced & 4 & 8.70 \\
Bachelor & 3 & 4.35 \\
Widower & 2 & 6.52 \\
\hline Living with: & & \\
Spouse / Partner & 19 & 41.30 \\
children & 22 & 47.83 \\
Single & 5 & 10.70 \\
\hline Risk factors: & & \\
Intense physical activity/ & 2 & 4.35 \\
sports & 5 & 10.87 \\
Knee injuries & 6 & 13.04 \\
Menopause & 7 & 15.22 \\
Wearing high-heeled shoes & 26 & 56.52 \\
Absence of risk factors & & \\
\hline
\end{tabular}

not notice the causes that could trigger the disease, thereby $15 \%$ of women reported wearing heels, and $13.04 \%$ were at menopause; likewise, physical activity and sports or trauma were detected in $4.35 \%$ and $10.87 \%$ of cases, respectively.

We continued the research by estimating the patient's age and the disease duration (Table 2). We concluded that patients with PsA had a mean age of
Table 2. Clinical-demographic parameters of the study group

\begin{tabular}{ccc}
\hline Parameters & Duration & $\begin{array}{c}\text { Variation } \\
\text { interval }\end{array}$ \\
\hline $\begin{array}{c}\text { Mean age at the time } \\
\text { of the research, years }\end{array}$ & $47.23 \pm 9.2$ & $19-70$ \\
\hline $\begin{array}{c}\text { Mean duration } \\
\text { of the disease, months }\end{array}$ & $164.78 \pm 92.81$ & $15-502$ \\
\hline $\begin{array}{c}\text { Time from the onset of } \\
\text { arthritis, months }\end{array}$ & $28.22 \pm 38.51$ & $13-104$ \\
\hline
\end{tabular}

48 years (aged between 19 and 70 years). Regarding the duration of the disease, it varied widely $(15-502$ months), with a mean of 164 months, which is about 14 years.

According to the objectives, we used international indices to assess the activity of the disease: DAPSA, which is the gold standard, and BASDAI, used in patients with axial impairment. The results of the disease activity assessment by DAPSA index are presented in Figure 1.

The analysis of the data presented in Figure 1 demonstrates that the mean \pm SD disease activity according to the DAPSA index was $27.33 \pm 15.76$ points, with wide variational interval, from 9.2 to 74.6 points. About 2/3 of the index level was within the limits of $15-30$ points. Subsequently, we segregated the activity of the disease according to the status of the DAPSA index in remission, low, moderate and high activity (Figure 2). The data reflect that at the time of inclusion in the study, no remission was found in the subjects, at the same time low activity was detected in

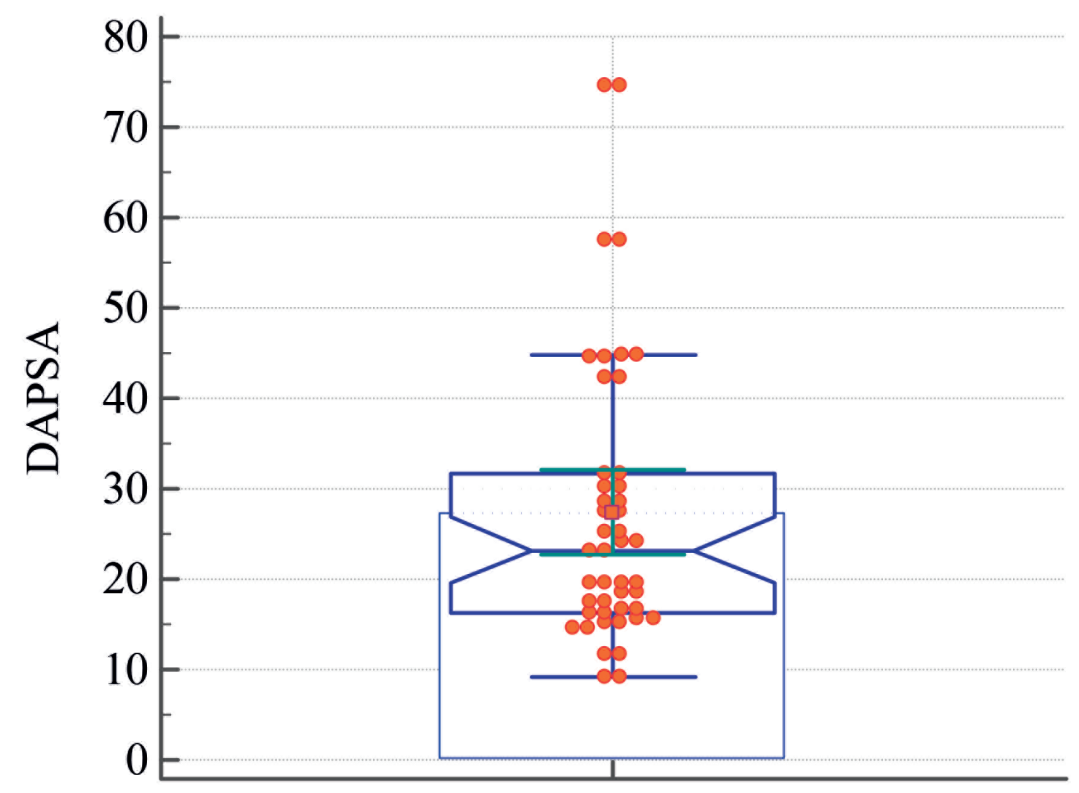

Figure 1. The activity of PsA according to the DAPSA index in the study group. 


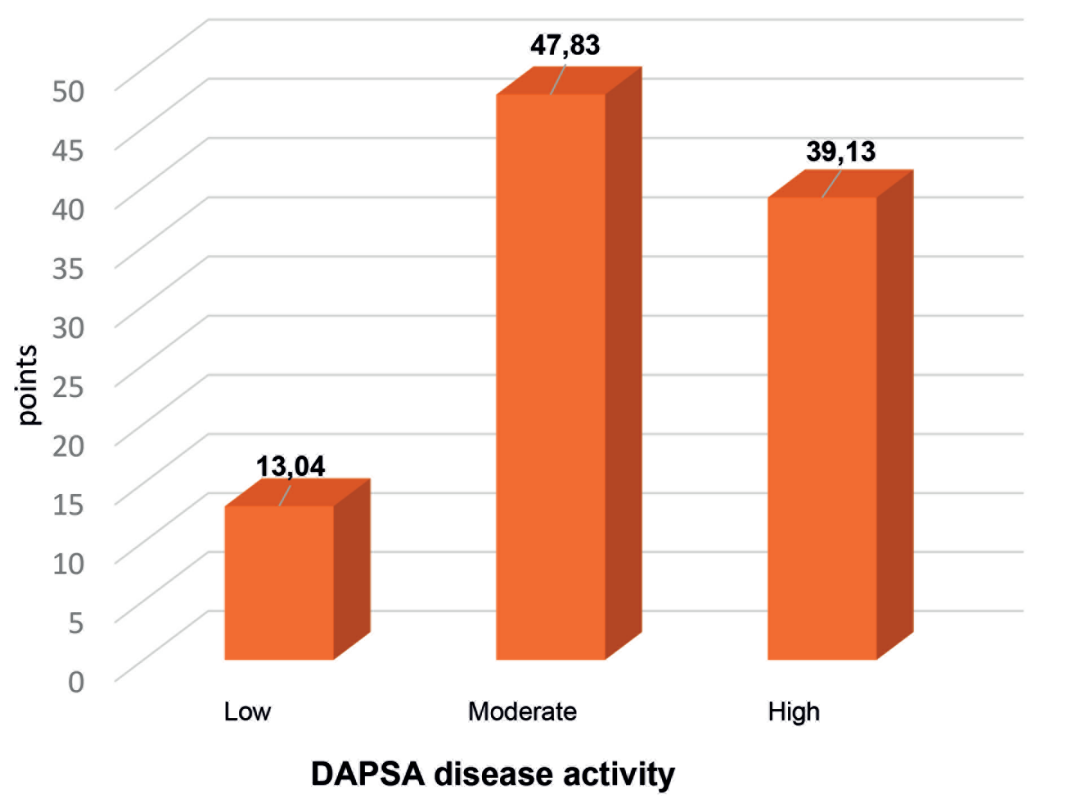

Figure 2. Psoriatic arthritis activity according to DAPSA

$13.04 \%$, moderate in $47.83 \%$ and high disease activity was detected in $39.13 \%$ of cases.

We determined the activity through another important index used in rheumatology, BASDAI (Figure 3). The examination of the BASDAI activity results related a mean $\pm \mathrm{SD}$ of 5.27 \pm 1.84 (between 2.4-9.6 p), considered high in 24 (26.09\%) patients, which represent similar data with Cerlat et al $(2011)^{10}$ and differ from the data of Wong et al (2012) ${ }^{7}$. Regarding the score with moderate values, there were 52 (56.52\%) subjects in our study. At the same time, the score with low values was found in $17.39 \%$ of patients ${ }^{11}$.

Consequently, we were interested in researching the group of patients through the Minimal Disease Activity Index, revised in 2019 by Coates ${ }^{12}$, to determine the number of patients with disease minimal activity or remission and their proportion in the research group (Table 3). The data show that only 4 patients (8.69\%) did not present symptoms like joint pain, while the absence of the swollen joints was more frequent, in $39.13 \%$ of cases, which means that the pain predominated. The pain assessed by VAS coincided with the painful joints - TJA. An index taken into account was the overall self-assessment (PGA), which showed that only $6(13.04 \%)$ patients out of the 46 examined rated their condition as good (less than $20 \mathrm{~mm}$ ), the enthesitis score in one third of the examined subjects was less than one, considered low. The PhGA included in HAQ was detected in a low level (below 0.5 points) in $26(56.52 \%)$ subjects. Thus, analyzing the data presented in Table 3 , we highlighted that only four (8.69\%) patients had minimal disease activity.

We intended to evaluate the groups according to the main indices used in PsA (Table 4). The analysis of the parameters, according to the clinical instruments, from the patient's research file is presented, respectively eight parameters. One of the parameters evaluated was the TJC and we noted the predominance of the moderate value (39.14\%), while the severe and low values were also frequent (26.08\%). The evaluation of the swollen joints showed the absence of swelling in $17.39 \%$ of cases, the predominant number reflected in the low value score group, observed in $47.83 \%$ patients. At the same time, we estimated the skin involvement in patients from the study group, highlighting the score with moderate values in $65.22 \%$ of subjects as the most frequent. We were interested in assessing pain and general

Table 3. Criteria for the Minimal Disease Activity Index in the study group

\begin{tabular}{cccc}
\hline Parameters & $\begin{array}{c}\text { Patient's } \\
\text { number }\end{array}$ & $\%$ & $\boldsymbol{v}-\boldsymbol{i}$ \\
\hline TJC & 4 & 8.69 & $0-1.0$ \\
\hline SJC & 18 & 39.13 & $0-1.0$ \\
\hline PASI & 2 & 4.34 & $0-1.0$ \\
\hline VAS & 4 & 8.69 & $0-15.0$ \\
\hline PGA & 6 & 13.04 & $0-20.0$ \\
\hline HAQ & 26 & 56.52 & $0-0.5$ \\
\hline MASES & 14 & 30.43 & $0-1.0$ \\
\hline
\end{tabular}


Table 4. Clinical parameters in patients with psoriatic arthritis $(n=46)$

\begin{tabular}{|c|c|c|c|c|c|c|c|c|}
\hline \multirow{2}{*}{ Indices } & \multicolumn{2}{|c|}{ Value 0 -remission } & \multicolumn{2}{|c|}{ Low value score } & \multicolumn{2}{|c|}{ Moderate value score } & \multicolumn{2}{|c|}{ High value score } \\
\hline & No. $(\%)$ & Gradation & No. $(\%)$ & Gradation & No. (\%) & Gradation & No. (\%) & Gradation \\
\hline TJC (No) & $4(8.70)$ & 0 & $\begin{array}{c}12 \\
(26.08) \\
\end{array}$ & $1-4$ & $18(39.14)$ & $5-10$ & $12(26.08)$ & $>10$ \\
\hline $\mathrm{SJC}(\mathrm{No})$ & $8(17.39)$ & 0 & $22(47.83)$ & $1-3$ & $2(4.35)$ & $4-5$ & $14(30.43)$ & $>5$ \\
\hline PASI (p) & $2(4.35)$ & $0-1$ & $12(26.08)$ & $2-10$ & $30(65.22)$ & $11-40$ & $2(4.35)$ & $>40$ \\
\hline PGA $(\mathrm{mm})$ & $0(0)$ & $0-10$ & $8(17.39)$ & $10-30$ & $22(47.83)$ & $40-70$ & $16(34.78)$ & $>70$ \\
\hline VAS $(\mathrm{mm})$ & $2(4.35)$ & $0-10$ & $4(8.70)$ & $10-30$ & $26(56.52)$ & $40-70$ & $14(30.43)$ & $>70$ \\
\hline DAPSA (p) & $0(0)$ & 0.4 & $6(13.04)$ & $5-14$ & $22(47.83)$ & $15-28$ & $18(39.13)$ & $>28$ \\
\hline BASDAI (p) & $0(0)$ & 0 & $11(23.91)$ & $1-3$ & $26(56.52)$ & $4-6$ & $9(19.57)$ & $>6$ \\
\hline MASES (p) & $2(4.35)$ & 0 & $32(69.57)$ & $1-4$ & $10(21.73)$ & $5-10$ & $2(4.35)$ & $>10$ \\
\hline
\end{tabular}

Table 5. Mean values of the clinical activity in the study lot $(\mathrm{n}=46)$

\begin{tabular}{ccc}
\hline Parameter & Mean value \pm SD & Variational interval \\
\hline VAS $(\mathrm{mm})$ & $55.13 \pm 18.81$ & $19-81$ \\
\hline PGA $(\mathrm{mm})$ & $60.17 \pm 16.85$ & $25-84$ \\
\hline MDGA (mm) & $58.09 \pm 16.88$ & $22-85$ \\
\hline PASI (points) & $20.21 \pm 9.69$ & $0.6-46.8$ \\
\hline DAPSA (points) & $27.33 \pm 15.76$ & $9.2-74.6$ \\
\hline BASDAI (points) & $5.27 \pm 1.84$ & $2.4-9.6$ \\
\hline MASES (points) & $3.09 \pm 2.20$ & $0-8$ \\
\hline
\end{tabular}

Table 6. Correlative analysis of the main clinical parameters $(n=46)$

\begin{tabular}{ccccccccc}
\hline Parameters & DAPSA & BASDAI & MDGA & PGA & VAS & MASES & TJC & SJC \\
\hline \multirow{2}{*}{ DAPSA } & & $\mathrm{r}=0.48$ & $\mathrm{r}=0.53$ & $\mathrm{r}=0.55$ & $\mathrm{r}=0.45$ & $\mathrm{r}=0.27$ & $\mathrm{r}=0.92$ & $\mathrm{r}=0.82$ \\
& & $\mathrm{p}=0.0007$ & $\mathrm{p}=0.0002$ & $\mathrm{p}=0.0001$ & $\mathrm{p}=0.0001$ & $\mathrm{p}=0.06$ & $\mathrm{p}<0.0001$ & $\mathrm{p}<0.0001$ \\
\hline \multirow{2}{*}{ BASDAI } & $\mathrm{r}=0.48$ & & $\mathrm{r}=0.25$ & $\mathrm{r}=0.24$ & $\mathrm{r}=0.49$ & $\mathrm{r}=0.42$ & $\mathrm{r}=0.35$ & $\mathrm{r}=0.33$ \\
& $\mathrm{p}=0.0007$ & & $\mathrm{p}=0.08$ & $\mathrm{p}=0.05$ & $\mathrm{p}=0.0004$ & $\mathrm{p}=0.03$ & $\mathrm{p}=0.01$ & $\mathrm{p}=0.06$ \\
\hline \multirow{2}{*}{ MDGA } & $\mathrm{r}=0.53$ & $\mathrm{r}=0.25$ & & $\mathrm{r}=0.95$ & $\mathrm{r}=0.64$ & $\mathrm{r}=0.16$ & $\mathrm{r}=0.36$ & $\mathrm{r}=0.31$ \\
& $\mathrm{p}=0.0002$ & $\mathrm{p}=0.08$ & & $\mathrm{p}<0.0001$ & $\mathrm{p}<0.0001$ & $\mathrm{p}=0.2$ & $\mathrm{p}=0.01$ & $\mathrm{p}=0.03$ \\
\hline \multirow{2}{*}{ PGA } & $\mathrm{r}=0.55$ & $\mathrm{r}=0.24$ & $\mathrm{r}=0.95$ & & $\mathrm{r}=0.54$ & $\mathrm{r}=0.21$ & $\mathrm{r}=0.37$ & $\mathrm{r}=0.33$ \\
& $\mathrm{p}=0.0001$ & $\mathrm{p}=0.1$ & $\mathrm{p}<0.0001$ & & $\mathrm{p}=0.0001$ & $\mathrm{p}=0.1$ & $\mathrm{p}=0.001$ & $\mathrm{p}=0.02$ \\
\hline \multirow{2}{*}{ VAS } & $\mathrm{r}=0.45$ & $\mathrm{r}=0.49$ & $\mathrm{r}=0.64$ & $\mathrm{r}=0.54$ & & $\mathrm{r}=0.47$ & $\mathrm{r}=0.28$ & $\mathrm{r}=0.12$ \\
& $\mathrm{p}=0.0001$ & $\mathrm{p}=0.0004$ & $\mathrm{p}<0.0001$ & $\mathrm{p}=0.0001$ & & $\mathrm{p}=0.001$ & $\mathrm{p}=0.05$ & $\mathrm{p}=0.3$ \\
\hline \multirow{2}{*}{ MASES } & $\mathrm{r}=0.27$ & $\mathrm{r}=0.42$ & $\mathrm{r}=0.16$ & $\mathrm{r}=0.21$ & $\mathrm{r}=0.47$ & & $\mathrm{r}=0.18$ & $\mathrm{r}=0.11$ \\
& $\mathrm{p}=0.06$ & $\mathrm{p}=0.03$ & $\mathrm{p}=0.2$ & $\mathrm{p}=0.1$ & $\mathrm{p}=0.001$ & & $\mathrm{p}=0.2$ & $\mathrm{p}=0.4$ \\
\hline \multirow{2}{*}{ TCJ } & $\mathrm{r}=0.92$ & $\mathrm{r}=0.35$ & $\mathrm{r}=0.36$ & $\mathrm{r}=0.37$ & $\mathrm{r}=0.28$ & $\mathrm{r}=0.18$ & & $\mathrm{r}=0.74$ \\
& $\mathrm{p}<0.0001$ & $\mathrm{p}=0.01$ & $\mathrm{p}=0.01$ & $\mathrm{p}=0.001$ & $\mathrm{p}=0.05$ & $\mathrm{p}=0.2$ & & $\mathrm{p}<0.0001$ \\
\hline \multirow{2}{*}{ SJC } & $\mathrm{r}=0.92$ & $\mathrm{r}=0.33$ & $\mathrm{r}=0.31$ & $\mathrm{r}=0.33$ & $\mathrm{r}=0.12$ & $\mathrm{r}=0.11$ & $\mathrm{r}=0.74$ & $\mathrm{p}$ \\
& $\mathrm{p}<0.0001$ & $\mathrm{p}=0.02$ & $\mathrm{p}=0.03$ & $\mathrm{p}=0.02$ & $\mathrm{p}=0.3$ & $\mathrm{p}=0.4$ & $\mathrm{p}<0.0001$ & $\mathrm{r}=0.15$ \\
\hline \multirow{2}{*}{ HAQ } & $\mathrm{r}=0.24$ & $\mathrm{r}=0.05$ & $\mathrm{r}=0.05$ & $\mathrm{r}=0.08$ & $\mathrm{r}=0.05$ & $\mathrm{r}=0.24$ & $\mathrm{r}=0.21$ & $\mathrm{p}=0.3$ \\
\hline & $\mathrm{p}=0.05$ & $\mathrm{p}=0.7$ & $\mathrm{p}=0.6$ & $\mathrm{p}=0.5$ & $\mathrm{p}=0.6$ & $\mathrm{p}=0.09$ & $\mathrm{p}=0.16$ & $\mathrm{p}=0.6$ \\
\hline
\end{tabular}

condition through self-administered VAS and PGA instruments. In fact, we obtained a small discrepancy between the general condition and the pain, PGA appreciated more severe. Of particular interest was the enthesial score, MASES, which objectifies enthesopathies by assessing the presence or absence of tenderness in the 13 enthesial sites and is considered an important tool in the evaluation of psoriatic arthritis.
The results of the enthesopathies evaluation showed low values in most of the patients, $73.91 \%$ cases. In conclusion, based on the obtained results, the most affected areas were pain and general condition, objectified by PGA.

The data from the Table 5 show that patients had pain variated from 19 to $81 \mathrm{~mm}$, with the mean value of 55.13 - moderate pain. Regarding to patient 


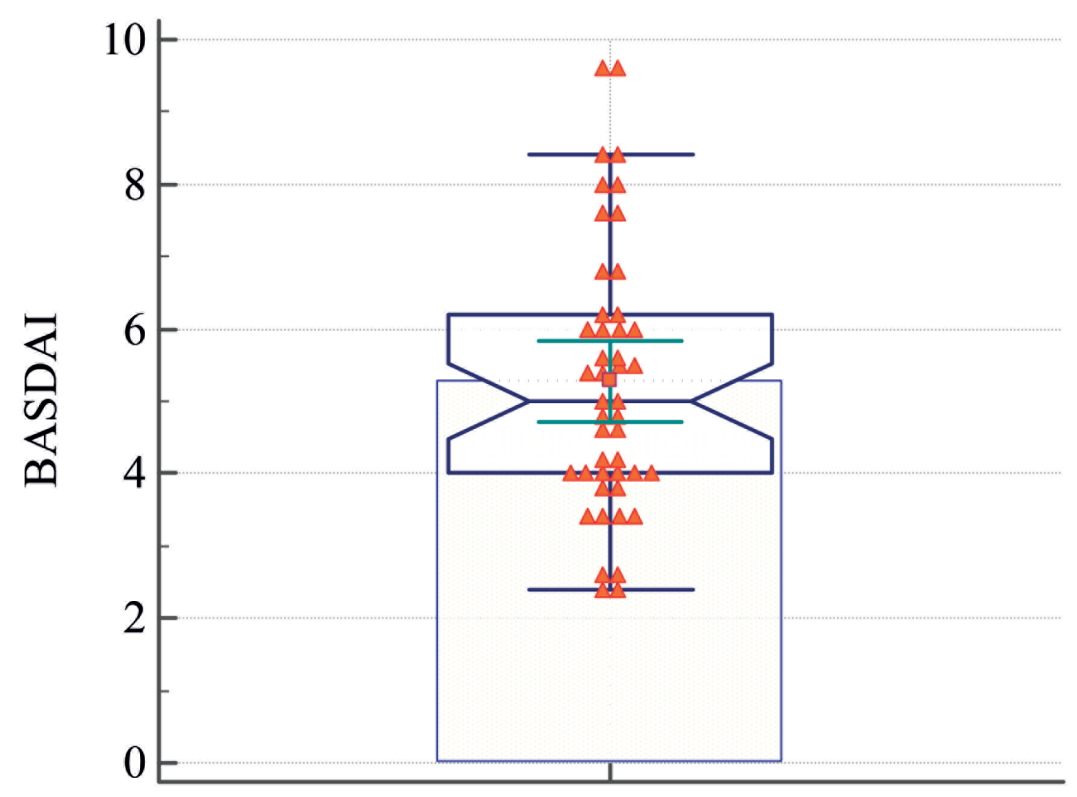

Figure 3. PsA activity according to the BASDAI index in the study group

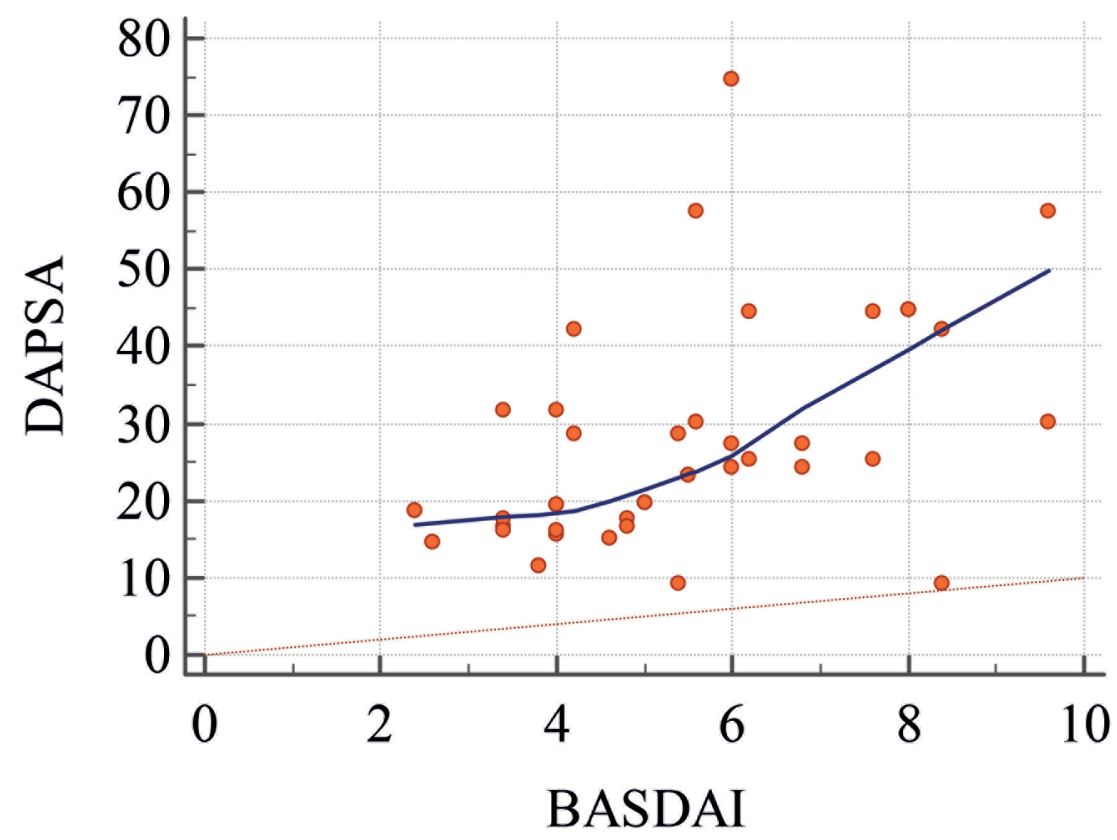

Figure 4. The correlation of DAPSA and BASDAI activity indices in the study group.

and physician global assessments we note the similar values, however patient's appreciation was higher than the doctor's within $2 \mathrm{~mm}$ in average. The disease activity assessment by DAPSA and BASDAI obtained the moderate disease activity with the tendency to high activity appreciated by DAPSA. The enthesial score appreciated in patients from the study group showed to be low, 3.09 points in average. More than $60 \%$ of patients with PsA had cutaneous manifestations on the moment of the visit, thus the psoriatic disease activity was appreciated as moderate (mean PASI value 20.21 points).

We were interested in performing a correlative analysis of present activity disease indices. First, we analyzed the total DAPSA and BASDAI indices correlation and determined a moderate clinic significant correlation $(r=0.488, p=0.007)$ reflected in Figure 3 . These data show that both indices are effective in appreciation of disease activity in patients with PsA, in general; besides, we detected a link in these two 
indices, which means that the reliability of disease activity appreciation in our patients was high.

The correlative analysis of the indices we used for the appreciation of patient's general condition by himself or by the physician and the pain evaluation was correlated with all the indices, which influences the patient's general wellbeing.

In the context of interrelation of global assessment, we were interested to correlate the patient's and physician's global assessment, and attained a strong statistically significant correlation, $r=0.958$, $p<0.0001$ (Figure 4). The further correlations of activity indices are presented in Table 6.

As presented in Table 6, the important correlations were found in DAPSA with all activity measures, excluding enthesitis score. Concerning the BASDAI, we detected the relations with pain and enthesitis score as well as joint counts, in addition to DAPSA. Considering the VAS, it correlates with all indices, with exception of SJC. Distinguishing the enthesitis score, the correlation was noted only with BASDAI and VAS, which is influenced by the presence of non-articular pain and discomfort, and the subjectiveness of Bath score. The interdependence of joint counts and their influence on the most indices of disease activity is evident. The interrelation of activity indices and PASI score was not found, with the exception of patient's global assessment $(\mathrm{r}=0.283$, $p<0.008)$, which is evident, that psoriatic eruptions are causing a discomfort for patient, related with the patient's global score. An important issue in patient's appreciation was the assessment of disability or impact of the disease on his everyday life, which was appreciated by HAQ, and this index correlated $(\mathrm{r}=0.24, \mathrm{p}<0.05)$ only with DAPSA, thus being more representative by this activity index.

The correlative analysis of inflammatory markers revealed that the most sensible in our study was erythrocyte sedimentation rate (ESR), which correlated with all clinical tools, except for MASES, while the C-reactive protein (CRP) correlates with DAPSA, BASDAI and MASES scores.

\section{Discussion}

Psoriasis and PsA is included in the World Health Organization (WHO) and Global Burden of Disease (GBD) work. The goal of the activity measure tools in PsA is to assess and monitor the disease activity from the onset and its evolution, the applicability of basic treatment of PsA for optimizing the functionality and health-related quality of life (HRQOL), and to prevent structural damage. This can be done by aiming at remission or, if this cannot be achieved, low or minimal disease activity ${ }^{11,13}$.
Disease activity is determined using composite measures, in which multiple aspects of the disease are bent together in a total score of disease activity level. Thus, multiple disease activity measures are available and used in PsA. As a more PsA-specific measure, DAPSA was developed using the 66/68 joint count. For clinical practice, use of either DAPSA, BASDAI or MDA is helpful ${ }^{6}$. Although all measures are able to distinguish different levels of disease activity, studies have shown that disease activity level is often moderate. Disease activity in patients from this study was predominantly moderate to severe, in $2 / 3$ of subjects.

This study assessed the responsiveness of some composite measures in the usual care of PsA, including BASAI and DAPSA, which showed high objectivity. Regarding the relation of a disease activity measure and HRQOL, patients in MDA report better HRQOL than patients not in $\mathrm{MDA}^{14}$. The superiority of DAPSA and MDA in transversal study could be attributed to their multidimensionality, but also to the use of more extensive questionnaires than for VAS scores alone. The main indices are influenced by other factors than active disease: an increase in acute phase reactants-considered an objective measure of disease activity-can have other causes than an increase in PsA activity; in our study, the inflammatory markers correlated with both DAPSA and BASDAI. A composite measure needs the interpretation of a physician, who can choose a treatment strategy if a higher disease activity score has other causes than PsA activity, that is why the tools of the disease activity assessment must be complex, as against to PGA, VAS or MDGA, which also can be influenced by subjective factors. The global assessment of patients with PsA demonstrated levels higher than moderate, with the overestimation of the disease by patients in comparison with their doctors.

The important sign of the disease, which decreases the quality of life, is pain, which was moderate to high in our patients and interdependent with all the indices used by us. The close correlation of VAS was found with global assessments, DAPSA, BASDAI, MASES and TJC, only the number of swollen joints did not influence the patient's pain level. The correlative analysis of the activity assessment tools highlighted that DAPSA takes into consideration the most important measures for the activity appreciation; moreover, the sensibility of this index is confirmed by more objective MDGA correlation and inflammatory response. Obviously, the CRP, which is included in this index, likewise the ESR, not included, are related to DAPSA. The less important correlation of BASDAI with activity indices, including MDGA and SJC, can be explained by the specific 
questions in this questionnaire, which refers to axial spondylarthritis ${ }^{15}$, while patients with PsA do not always have these symptoms. The other cause, which can also be referred to the absence of correlation with the MDGA, could be the subjectiveness of the given questions in BASDAI index. As against to the DAPSA index, which consists of PGA and VAS evaluation and correlates significantly with the strong relation between these measures, BASDAI is less sensible in this appreciation. Besides, the DAPSA has a strong clinically significant correlation with the MDGA. In clinical practice, the assessment of the musculoskeletal disease activity ${ }^{16}$ should include all joints, presence of enthesitis and dactylitis; however, in our study the enthesial score did not show an important relation to other clinical tools, excepting BASDAI and VAS, but it is also important to evaluate these symptoms to create the full picture of the disease.

The assessment of every system implicated in the variety of the PsA clinical picture is important for the management of the disease. The time needed to perform all these clinical tools is important and the insufficient doctor's time guides the necessity of a one complex clinical tool for PsA disease activity appreciation.

\section{Conclusions}

Given the complexity of PsA, the estimation of disease activity needs to consider the important domains to assess their impact on the patient and the response to treatment. The disease activity measure DAPSA demonstrated the highest objectiveness and was more able to designate between different levels of disease activity. DAPSA together with MDA were best related to patient's quality of life. Therefore, assessing the activity of the disease by MDA and DAPSA can be recommended for use in the clinical practice.

\section{Authors' contribution}

T.R. and M.G. drafted the first manuscript, N.L.O. and M.G. acquired and interpreted the data, T.R., L.M.N. and M.M. designed the trial, M.M. and V.S., V.S.B. revised the manuscript critically. All the authors revised and approved the final version of the manuscript.

\section{Compliance with Ethics Requirements:}

"The authors declare no conflict of interest regarding this article"

"The authors declare that all the procedures and experiments of this study respect the ethical standards in the Helsinki Declaration of 1975, as revised in 2008(5), as well as the national law. Informed consent was obtained from all the patients included in the study"

"No funding for this study"

\section{Acknowledgments: none}

\section{REFEREnCES}

1. Kerschbaumer A, Fenzl KH, Erlacher L, Aletaha D. An overview of psoriatic arthritis - epidemiology, clinical features, pathophysiology and novel treatment targets Andreas. Wien Klin Wochenschr. 2016:128(21): 791-795.

2. Ogdie A, Wiess P. The epidemiology of psoriatic arthritis. Rheum Dis Clin North Am. 2015; 41(4): 545-568.

3. Chandran V, Maharaj AB. Assessing disease activity in psoriasis and psoriatic arthritis: impact on management and therapy. Expert Rev Clin Immunol. 2016:12(5):573-82.

4. Kalyoncu U, Ogdie A, Campbell W, et al. Systematic literature review of domains assessed in psoriatic arthritis to inform the update of the psoriatic arthritis core domain set. RMD Open. 2016:2(1):e000217.

5. Smolen JS, Schöls M, Braun J, et al. Treating axial spondylarthritis and peripheral spondylarthritis, especially psoriatic arthritis, to target: 2017 update of recommendations by an international task force. Ann Rheum Dis. 2018:77(1): 3-17.

6. Schoels M, Aletaha D, Alasti F, et al. Disease activity in psoriatic arthritis (PsA): defining remission and treatment success using the DAPSA score. Ann Rheum Dis. 2016:75(5):811-8

7. Wong PC, Leung YY, Li EK, Tam LS. Measuring disease activity in psoriatic arthritis. Int J Rheumatol. 2012:839425.

8. Gottlieb A, Merola JF. Psoriatic arthritis for dermatologists. Journal of Dermatological Treatment. 2019:31(7):662-679.

9. Cauli A, Gladman DD, Mathieu A, et al. Patient global assessment in psoriatic arthritis: a multicentre GRAPPA and OMERACT study. J Rheumatol. 2011:38(5):898-903.

10. Cerlat E, Gorea O, Mazur-Nicorici L, et al. Rolul instrumentelor clinice și radioimagistice în diagnosticul afectării axiale în artrita psoriazică. Analele Stiintifice ale USMF "Nicolae Testemitanu. 2011:12(3):114-119.

11. Gossec L, Smolen JS, Ramiro S, et al. European League Against Rheumatism (EULAR) recommendations for the management of psoriatic arthritis with pharmacological therapies: 2015 update. Ann Rheum Dis. 2016:75:499-510.

12. Coates LC, Strand V, Wilson H, et al. Measurement properties of the minimal disease activity criteria for psoriatic arthritis. RMD Open. 2019:5(2): e001002.

13. Coates LC, Kavanaugh A, Mease PJ, et al. Group for Research and Assessment of Psoriasis and Psoriatic Arthritis 2015 treatment recommendations for psoriatic arthritis. Arthritis Rheumatol. 2016:68:1060-71.

14. Gratacós, J, Daudén E, Gómez-Reino J, et al. Health-related quality of life in psoriatic arthritis patients in Spain. Reumatología Clínica (English Edition). 2014:10(1):25-31.

15. Cseppento C, Cevei M, Cioara F, Bungau S. Psychological and functional impact of HIP arthritis and coxita of rheumatoid arthritis and ankylosing spondylitis. Osteoporosis Int. 2011;22 (Suppl. 1):387-388.

16. Chadha S, Behl T, Kumar A, et al. Mechanistic insights into the role of pyroptosis in rheumatoid arthritis. Curr Res Translat Med. 2020; 68(4):151-158. 